\title{
O lugar da política linguística na formação inicial de professores de
}

\author{
alemão / The place of language policy in pre-service education of german \\ teachers
}

Dörthe Uphoff

Recebido em 23 jun. 2019. Aprovado em 25 ago. 2019

Como citar este artigo:

UPHOFF, Dörthe. O lugar da política linguística na formação inicial de professores de alemão / The place of language policy in pre-service education of german teachers. Revista Letras Raras. Campina Grande, v. 8, n. 3, p. Port. 112-130 /

Eng. 110-127, set. 2019. ISSN 2317-2347.

DOI: http://dx.doi.org/10.35572/rlr.v8i3.1467.

\section{RESUMO}

O artigo tem por objetivo investigar a importância da dimensão política na formação inicial de professores de línguas. Nesse intuito, apresentaremos, inicialmente, alguns modelos de competências necessárias ao ofício do professor na área (ALMEIDA FILHO, 2005; NEWBY et al., 2007; SCHART e LEGUTKE, 2012; KUMARAVADIVELU, 2012; ENDE et al., 2013) a fim de examinar a relevância que os autores atribuem a questões da política linguística. Argumentaremos em seguida, com base em Christ (1992), que a dimensão política não pode ser considerada um aspecto secundário do ensino de línguas, mas, ao contrário, deve ser vista como um elemento basilar que determina e estrutura as condições em que o ensino se dá em um dado contexto. Defenderemos, por esse motivo, que a política linguística precisa ser abordada já na formação inicial dos professores. Com base no exemplo do ensino de alemão no Brasil, pretendemos mostrar no final como o impacto da dimensão política no ensino de línguas ficou mais patente na conjuntura atual da globalização.

PALAVRAS-CHAVE: Formação inicial de professores; Alemão como língua estrangeira; Competências; Política linguística

\begin{abstract}
The article aims to investigate the importance of the political dimension in pre-service language teacher education. To this end, we will initially present some models of competences necessary to language teaching (ALMEIDA FILHO, 2005; NEWBY et al., 2007, SCHART and LEGUTKE, 2012; KUMARAVADIVELU, 2012; ENDE et al., 2013) in order to examine the relevance that these authors put on language policy in this context. Based on Christ (1992), we will then argue that the political dimension can not be considered a secondary aspect of language teaching, but rather should be seen as a basic element that determines as well as structures the conditions under which language teaching takes place in a given context. For this reason we will defend that language policy needs to be addressed already in pre-service teacher education. Based on the example of German teaching in Brazil, we will finally intend to show how the impact of the political dimension on language teaching has become more evident in the current conjuncture of globalization.
\end{abstract}

KEYWORDS: Pre-service teacher education; German as a foreign language; Competences; Language politics

\footnotetext{
* Professora Doutora, Universidade de São Paulo - USP, São Paulo, SP, Brasil, dorthe@ usp.br
} 


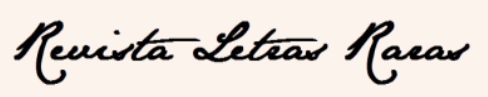

ISSN: $2317-2347$ - v. 8, n. 3 (2019)

\section{Introdução}

A formação do professor de alemão como língua estrangeira ${ }^{1}$ (doravante LE) costuma ser vista hoje como um processo cíclico e contínuo, que apenas inicia no curso de licenciatura (cf. KRUMM; RIEMER, 2010, p. 1342), precisando ser complementada por períodos regulares de formação continuada. Nesse cenário, a formação inicial tem a função de proporcionar ao licenciando uma competência linguística sólida, além de uma visão ampla e crítica em relação aos discursos didático-metodológicos que circulam na área (cf. UPHOFF, 2018). Outros saberes, como as múltiplas tarefas ligadas ao gerenciamento do ensino, são adquiridos aos poucos e precisam ser aprofundados e reciclados durante toda a vida profissional. Partindo dessa visão, perguntamo-nos qual a relevância de abordar aspectos políticos do ensino de alemão como língua estrangeira no âmbito da licenciatura, enquanto etapa inicial, mas obrigatória, do processo formativo. Em outras palavras, quais conhecimentos sobre a política linguística concernente ao ensino de alemão no Brasil poderiam ser enquadrados como essenciais, devendo ser trabalhados já durante o curso universitário? Num primeiro olhar, questões relacionadas à política linguística podem parecer de menor importância, dada a multiplicidade de competências didático-metodológicas esperadas de um professor de línguas hoje em dia (cf. seção 2). No entanto, objetivamos argumentar, ao longo do presente artigo, que a complexidade das relações internacionais no mundo globalizado exige um entendimento mais acurado também da dimensão política do ensino de idiomas, e pretendemos ilustrar nossa posição através do ensino de alemão na escola brasileira.

Para iniciar, vale lembrar que, de acordo com Rajagopalan (2013), “ainda há muita confusão ou, no mínimo indefinição, sobre o que exatamente significa o próprio termo política linguística” (RAJAGOPALAN, 2013, p. 19, grifo no original). O autor define o conceito como "a arte de conduzir reflexões em torno de línguas específicas, com o intuito de conduzir ações concretas de interesse público relativo à(s) língua(s) que importam para o povo de uma nação, de um estado ou ainda, instâncias

\footnotetext{
${ }^{1}$ No presente artigo, optamos pela expressão "língua estrangeira", em detrimento de "língua adicional", uma vez que é sob esse rótulo que o ensino de alemão em países distantes da Europa ainda costuma ser tratado na literatura especializada da área. Nos trechos reproduzidos de outros autores, iremos manter a expressão utilizada pelo autor em questão.
} 


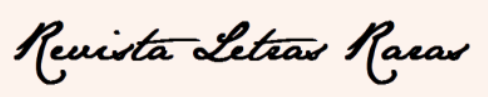

ISSN: $2317-2347$ - v. 8, n. 3 (2019)

transnacionais maiores (ibid., p. 21). Krumm (2016, p. 46), renomado especialista na área de alemão como língua estrangeira (doravante ALE), especifica que a política linguística pode se manifestar essencialmente de duas maneiras: por um lado, como política linguística oficial e explícita, fixada por meio de leis, diretrizes e regulamentos institucionais, e, por outro, como ação individual, quando uma pessoa demanda - ou rejeita - utilizar determinada língua. Para o âmbito do ensino de línguas, Krumm observa que não se costuma escolher livremente o(s) idioma(s) que se pretende aprender, mas que essa decisão está sujeita a fatores sociais, políticos e econômicos (KRUMM, 2016, p. 45). Em tempos de globalização acelerada, valorizam-se idiomas de prestígio internacional e econômico, como principalmente o inglês, em detrimento de outras línguas estrangeiras ou de uma educação plurilíngue mais diferenciada (cf. THÜRMANN, 2016). Um exemplo atual dessa conduta é a mudança da LDB promulgada pela lei $\mathrm{n}^{\mathrm{o}} 13.415$, de 16 de fevereiro de 2017, que torna obrigatório o ensino de inglês a partir do sexto ano, dificultando, por meio dessa determinação, a presença de outros idiomas, como o alemão, na grade curricular do ensino básico.

A seguir, apresentaremos alguns modelos de competências do professor de línguas propostos nos últimos anos, no intuito de identificar o papel que saberes relacionados a aspectos da política linguística desempenham neles. Examinaremos também as próprias noções de competência e saber subjacentes a esses referenciais, bem como a relação conceitual que existe entre os dois termos.

Na sequência, nosso objetivo é argumentar, seguindo a posição de Christ (1992), que a "política linguística não constitui um elemento qualquer do ensino-aprendizagem de línguas estrangeiras ao lado de outros, mas apresenta uma importância basilar para esse campo de ação"2 (CHRIST, 1992, p. 55, grifo no original). Nesse sentido, defendemos que aspectos relacionados à dimensão política do ensino de idiomas precisam ser abordados já na formação inicial do professor e não devem ser deixados para fases posteriores de formação continuada. A nosso ver, essa demanda se faz presente especialmente na atual conjuntura da globalização, que coloca os interesses políticos envolvidos no ensino-aprendizagem de determinadas línguas em maior

\footnotetext{
${ }^{2}$ No original: "Die Sprachenpolitik ist nicht irgendeine Komponente des Lehrens und Lernens fremder Sprachen neben anderen, sondern sie hat eine grundlegende Bedeutung für diesen Wirkungsbereich." Todas as citações originalmente formuladas em alemão ou inglês foram traduzidas pela autora do presente artigo.
} 


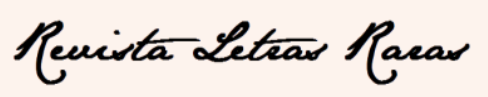

ISSN: 2317-2347 - v. 8, n. 3 (2019)

evidência. Ilustraremos nossa argumentação com exemplos envolvendo medidas políticas do governo da Alemanha que afetam o ensino de alemão na educação básica do Brasil.

\section{Formação docente: competências e saberes do professor de língua estrangeira}

De acordo com Kumaravadivelu (2012, p. 23), há uma "pletora de rótulos e definições" ${ }^{3}$ disponível na literatura especializada para discriminar os elementos que compõem a expertise do professor de línguas. Como observa Perrenoud (2000), "as facetas do trabalho pedagógico, as famílias de competências não existem “objetivamente”, elas são construídas, certamente a partir do real, mas também de tramas conceituais e de pré-conceitos teóricos e ideológicos" (PERRENOUD, 2000, p. 172, aspas e grifo no original). Desse modo, encontramos diversas propostas, com terminologia variada, para descrever as habilidades necessárias ao fazer docente na área do ensino de línguas. Seguindo uma tendência geral do discurso pedagógico, a maioria dos autores que consultamos utiliza o termo "competência" para designar o know-how do professor (cf., por exemplo, ALMEIDA FILHO, 2005; NEWBY et al., 2007; CONSOLO e PORTO, 2011; SCHART e LEGUTKE, 2012; ENDE et al., 2013; ENDE e MOHR, 2015); Kumaravadivelu (2012), por outro lado, evita a expressão, dando preferência ao termo "saber" (knowledge, no original inglês).

A seguir, apresentamos brevemente alguns modelos de competências/saberes do professor de língua estrangeira propostos por esses autores, no intuito de avaliar qual o papel atribuído à política linguística nesses conjuntos. Antes, no entanto, gostaríamos de dar alguns esclarecimentos gerais sobre os conceitos de saber e competência, no âmbito da formação docente.

Perrenoud (2000, p. 15) define competência como a "capacidade de mobilizar diversos recursos cognitivos para enfrentar um tipo de situações". Segundo ele, "as competências não são elas mesmas saberes, savoir-faire ou atitudes, mas mobilizam, integram e orquestram tais recursos" (ibid.). Na mesma linha, também Ende e Mohr (2015), com base no Quadro Europeu Comum de Referência para Línguas

\footnotetext{
${ }^{3}$ No original: "plethora of labels and definitions"
} 


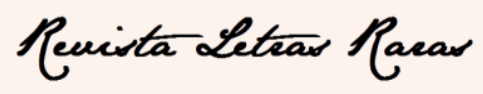

ISSN: 2317-2347 - v. 8, n. 3 (2019)

(CONSELHO DA EUROPA, 2001), enxergam a competência como "a soma do saber (declarativo), das habilidades (procedurais) e competências ligadas à personalidade [persönlichkeits-bezogene Kompetenzen] que permitem ao ser humano realizar ações"4 (ENDE; MOHR, 2015, p. 27). Como observam Schart e Legutke (2012, p. 53), há uma estreita relação entre saber e saber-fazer (Wissen e Können, no original alemão), inerente ao conceito da competência.

Ende e Mohr (2015, p. 62-63) diferenciam ainda entre saber explícito e saber implícito, relacionando o primeiro tipo a conhecimentos declarativos, que podem ser enunciados e, portanto, avaliados como corretos ou errados, e o segundo tipo ao saberfazer (Können), descrito também em Perrenoud pela expressão francesa savoir-faire. Essa modalidade do saber denota habilidades que uma pessoa domina sem poder explicitá-las clara e exaustivamente, como é o caso, por exemplo, de atividades esportivas ou raciocínios mentais.

No Brasil, uma das propostas mais conhecidas para o conjunto de competências ligadas ao ofício do professor de línguas foi feita por Almeida Filho. Em sua obra de 2005, o autor resume as competências da seguinte forma:

Competência implícita (que se desenvolve em nós a partir das experiências de aprender língua(s) que vivemos), competência teórica (corpo de conhecimentos que podemos enunciar), competência aplicada (o ensino que podemos realizar orientado e explicitado pela competência teórica que temos), competência linguísticocomunicativa (a língua que se sabe e se pode usar) e a competência profissional (nosso reconhecimento do valor de ser professor de língua, nossa responsabilidade pelo avanço profissional próprio e dos outros através da reflexão e das ações correspondentes) (ALMEIDA FILHO, 2005, p. 94).

Comparando o modelo com os conceitos de competência e saber discutidos há pouco, é possível relacionar a competência teórica prevista por Almeida Filho com o saber declarativo ou explícito identificado por Ende e Mohr (2015). As competências implícita e aplicada, por sua vez, podem ser associadas ao que as autoras denominam como Können, ou habilidades procedurais, sendo que a competência implícita ainda se relaciona com o saber implícito assinalado pelas autoras. $\mathrm{O}$ equivalente à competência profissional estipulada por Almeida Filho não é tão claramente identificável, mas,

\footnotetext{
4 No original: “die Summe des (dekarativen) Wissens, der (prozeduralen) Fertigkeiten und der persönlichkeitsbezogenen Kompetenzen, die es einem Menschen erlauben, Handlungen auszuführen“"
} 


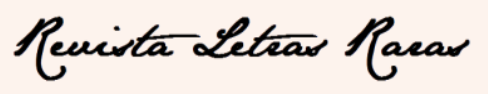

ISSN: $2317-2347$ - v. 8, n. 3 (2019)

talvez, possa ser aproximado às competências pessoais de Ende e Mohr (2015), ou ainda ao que Perrenoud (2000) formula como atitudes.

De acordo com Consolo e Porto (2011, p. 75), o referencial proposto por Almeida Filho continua sendo "o mais adequado para a atualidade" e, em consequência, também é adotado por esses autores. Para nossa finalidade, no entanto, o modelo carece de informações específicas sobre o papel da política linguística na formação do professor e, por isso, não será contemplado na discussão posterior (cf. seção 3).

Passemos agora para outra proposta de modelo para descrever as competências necessárias ao ofício do professor de línguas. Newby et al. (2007), encarregados pelo Conselho da Europa, apresentam um portfólio com 193 descritores de competências destinado ao profissional em formação. O material visa ser um instrumento de reflexão e autoavaliação durante a trajetória formativa do professor. Dividido em sete categorias (contexto, metodologia, recursos, planejamento de aula, regência de aula, aprendizagem autônoma e avaliação), o manual oferece alguns descritores relacionados a aspectos da política linguística na categoria contexto, quando trata de questões curriculares do ensino de línguas. Assim, encontramos, por exemplo, os seguintes enunciados:

Compreendo as diretrizes estabelecidas nos parâmetros curriculares nacionais e locais.

Sou capaz de preparar e dar aula de acordo com os parâmetros curriculares nacionais e locais.

Compreendo os princípios contidos nos documentos europeus (p. ex. Quadro Europeu Comum de Referência para Línguas, Portfólio Europeu de Línguas).

Compreendo os documentos europeus (p. ex. Quadro Europeu Comum de Referência para Línguas, Portfólio Europeu de Línguas) e sou capaz de integrar seu teor à minha aula, se for o caso (NEWBY et al., 2007, p. 15$)^{5}$.

Vale ressaltar que os descritores envolvendo explicitamente a dimensão política do ensino de línguas são pouco numerosos na obra de Newby et al. (2007), sendo que os mesmos focalizam, em sua maioria, o conhecimento das diferentes diretrizes curriculares que orientam o ensino, além da competência de desenvolver o fazer

\footnotetext{
${ }^{5}$ No original: "Ich verstehe die in nationalen und lokalen Lehrplänen festgelegten Anforderungen. / Ich kann anhand der Anforderungen in nationalen und lokalen Lehrplänen Sprachunterricht gestalten. / Ich verstehe die in den entsprechenden europäischen Dokumenten enthaltenen Grundsätze (z.B. die des Gemeinsamen europäischen Referenzrahmens für Sprachen, des Europäischen Sprachenportfolios). / Ich verstehe die europäischen Dokumente (z.B. die des Gemeinsamen europäischen Referenzrahmens für Sprachen, des Europäischen Sprachenportfolios) und kann deren Inhalt gegebenenfalls in meinen Unterricht integrieren."
} 


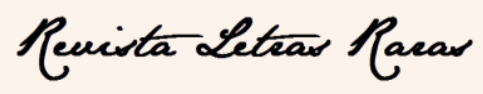

ISSN: $2317-2347$ - v. 8, n. 3 (2019)

pedagógico de acordo com elas. A política linguística aparece aqui, portanto, como um condicionante geral do ensino de idiomas que precisa ser reconhecido e acatado pelo professor.

Essa conduta também prevalece na série Deutsch Lehren Lernen (DLL), publicada desde 2012 pelo Instituto Goethe para fins de formação inicial e continuada do professor de ALE. ${ }^{6}$ No primeiro volume da série, dedicado às competências necessárias ao ofício do professor, Schart e Legutke (2012, p. 55-57) diferenciam os seguintes tipos de competência: didática, organizatória, pessoal, comunicativa, teórica e interpessoal. Mesmo não entrando em detalhes sobre as características dessas competências, é possível notar, já pelas suas denominações, que as habilidades metodológicas do ensino predominam no conjunto. Não há, nos exemplos fornecidos pelos autores, nenhuma menção explícita a documentos políticos que possam influenciar o ensino. No sexto volume da série, por outro lado, intitulado "Diretrizes curriculares e planejamento de aula" (Curriculare Vorgaben und Unterrichtsplanung, cf. ENDE et al., 2013), o leitor é incentivado a informar-se sobre os parâmetros curriculares que orientam o ensino:

Em muitos países, o ensino de alemão como o de outras matérias é regulamentado por diretrizes de ministérios ou outras instituições, às vezes até de forma bastante detalhada. Define-se nelas o que precisa ser aprendido e os professores precisam "passar" esse conteúdo. Não obstante, na prática, nem sempre estamos cientes dessas normas. Orientamo-nos por livros didáticos e provas oficiais sem nos inteirarmos sobre os objetivos da política educacional traçados por meio deles. Talvez você até se pergunte: "O que adianta eu saber mais a respeito? As instituições é que precisam cuidar disso! Já me dá trabalho o suficiente dar uma boa aula". Mas as diretrizes ministeriais certamente exercem influência sobre a margem de liberdade que você tem em sala de aula (ENDE et al., 2013, p. 8, aspas no original) ${ }^{7}$.

\footnotetext{
${ }^{6}$ Cf. o sítio eletrônico [https://www.goethe.de/de/spr/unt/for/dll.html] (Acesso em: 20/06/2019) para maiores detalhes do material.

${ }^{7}$ No original: "In vielen Ländern werden der Deutschunterricht wie auch der Unterricht in den übrigen Fächern über Vorgaben von Ministerien und anderen Institutionen zum Teil bis ins Detail festgelegt. Es wird vorgeschrieben, was gelernt werden soll, und die Lehrenden müssen dann mit dem Stoff „,durchkommen“. Auch wie sie dabei vorgehen sollen, ist zum Teil festgeschrieben. Allerdings ist man sich in der Praxis nicht immer der Vorgaben bewusst. Man hält sich an Lehrwerke und vorgeschriebene Prüfungen, ohne genau darüber informiert zu sein, welche bildungspolitischen Ziele damit verfolgt werden. Vielleicht fragen Sie sich sogar: ,Was nützt es mir eigentlich, wenn ich darüber Bescheid weiß? Sollen sich doch die Institutionen darum kümmern! Ich habe schon genug damit zu tun, dass ich einen guten Unterricht gebe. "Doch ministerielle Vorgaben haben natürlich einen Einfluss auf Ihren Spielraum im Unterricht."
} 


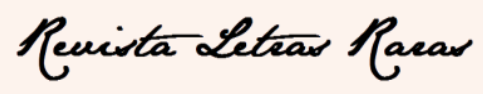

ISSN: $2317-2347$ - v. 8, n. 3 (2019)

Observa-se, aqui, outro aspecto relacionado às competências do professor de línguas: a importância daquilo que o próprio professor, enquanto destinatário das medidas de formação inicial e continuada, reconhece como competência necessária a seu ofício. Como mostra o próximo excerto, Ende et al. (2015) não têm a expectativa de que seus leitores possam ter muitos conhecimentos acerca da dimensão política do ensino de alemão:

Você notará que apresentaremos, no primeiro capítulo, diversas informações que devem ser [...] novas para você. Não obstante, tratase de informações importantes sobre o Quadro, parâmetros e orientações curriculares que acarretam consequências para a sua aula, embora geralmente de forma indireta - p. ex. através de livros didáticos e provas. Mas mesmo quando esses efeitos se manifestam apenas indiretamente, você precisa conhecê-los para estar em condições de decidir como otimizar o seu campo de ação (ENDE et al., 2013, p. 9$)^{8}$.

Sigamos agora para um último modelo de formação docente na área de línguas: a proposta "KARDS" de Kumaravadivelu (2012). Esse modelo está constituído por componentes modulares: saber [Knowing], analisar [Analzying], reconhecer [Recognizing], fazer [Doing] e ver [Seeing], formando o acrônimo "KARDS" em inglês. Nas palavras do autor:

Ao identificar esses componentes, levei em consideração o que os professores precisam fazer, essencialmente, para se tornarem indivíduos autodeterminados e autotransformadores. Eles precisam (a) desenvolver seus saberes profissionais, procedurais e pessoais; (b) analisar as necessidades dos aprendizes, sua motivação e autonomia; (c) reconhecer suas próprias identidades, crenças e valores; (d) produzir o ensino, teorizar e dialogar; e (e) monitorar seus próprios atos de ensino (KUMARAVADIVELU, 2012, p. 17) ${ }^{9}$.

Encontram-se elementos explícitos da dimensão política do ensino de línguas nos módulos Knowing e Analyzing. Como pode ser depreendido do último trecho citado, Kumaravadivelu subdivide o primeiro módulo em conhecimentos profissionais, procedurais e pessoais. O saber profissional, segundo ele, "representa o conteúdo

\footnotetext{
${ }^{8}$ No original: "Sie werden merken, dass wir Ihnen in Kapitel 1 recht viele Informationen präsentierren, die für Sie [zum Teil] neu sein dürften. Bei diesen Informationen zum GER, zu Leistungsstandards und zu Curricula/Lehrplänen handelt es sich allerdings um für Sie wichtige Hintergrundinformationen, die sich auf Ihren Unterricht auswirken, in der Regel allerdings eher indirekt - z.B. über Lehrwerke und Prüfungen. Doch auch, wenn der Einfluss sich lediglich indirekt auswirkt, sollten Sie ihn kennen, um dann entscheiden zu könen, wie Sie Ihren eigenen Handlungsspielraum möglichst optimal gestalten können.“

${ }^{9}$ No original: "In identifying these components, I have kept in mind what teachers have to basically do in order to become self-determining and self-transforming individuals. They have to (a) develop their professional, procedural and personal knowledge base; (b) analyze learner needs, motivation, and autonomy; (c) recognize their own identities, beliefs and values; (d) perform teaching, theorizing and dialogizing; and (e) monitor their own teaching acts."
} 


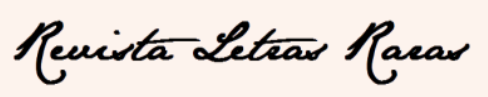

ISSN: 2317-2347 - v. 8, n. 3 (2019)

intelectual de uma disciplina, uma compilação de fatos, teorias e conceitos"10 (KUMARAVADIVELU, 2012, p. 24). O saber procedural, por sua vez, está ligado à "habilidade de gerenciar a aprendizagem em sala de aula de modo efetivo""11 (ibid., p. 31), ao passo que o saber pessoal indica o conjunto das reflexões e intuições do professor a respeito do que pode ser considerado uma boa aula (cf. ibid., p. 32). Notamos, aqui, certa semelhança com outros conceitos já discutidos. Assim, o saber profissional configura um saber declarativo e explícito, na terminologia de Ende e Mohr (2015), coincidindo largamente com que Almeida Filho (2005) chama de "competência teórica". O saber procedural, por sua vez, corresponde ao Können, ou saber-fazer, proposto por Ende e Mohr (2015) com base na terminologia proposta pelo Quadro Europeu Comum de Referência para Línguas (CONSELHO DA EUROPA, 2001).

Ora, é interessante observar que Kumaravadivelu e Almeida Filho, apesar de conceberem categorias muito próximas, escolhem critérios diferentes para distinguir entre saber procedural e pessoal, e competência aplicada e implícita, respectivamente. Nota-se que, para Kumaravadivelu, o critério que separa ambas as categorias reside no binômio coletivo/individual: o saber procedural deriva da "sabedoria coletiva do especialista” (KUMARAVADIVELU, 2012, p. 32), enquanto que o saber pessoal "reflete o esforço individual"12 (ibid.) do professor em construir, ao longo da carreira, o seu "senso de plausibilidade" (cf. PRABHU, 1990). Almeida Filho (2005, p. 94), por outro lado, mobiliza o binômio explícito/implícito para diferenciar a competência aplicada - desenvolvida pela competência teórica e, portanto, explícita - da competência implícita. Essa sutil diferença será retomada mais para frente (cf. seção 4).

Como já foi dito, no modelo KARDS, questões relativas à política linguística aparecem sobretudo na categoria do saber profissional do módulo Knowing. O saber profissional é subdividido por Kumaravadivelu (2012) em saberes concernentes a língua, aprendizagem de língua e ensino de língua. No âmbito do saber vinculado à aprendizagem de línguas, o autor identifica, entre outros,

fatores educacionais como políticas linguísticas e planejamento linguístico [language policies and language planning] estabelecidos por agências governamentais e educacionais. Esses fatores

\footnotetext{
${ }^{10}$ No original: "[It] represents the intellectual content of the discipline, a compilation of facts, theories, and concepts."

${ }^{11}$ No original: "ability to manage classroom language learning effectively"

${ }^{12}$ No original: "[If professional and procedural knowledge systems represent the] collective wisdom of the expert, [personal knowledge] reflects the individual endeavor [of the teacher]."
} 


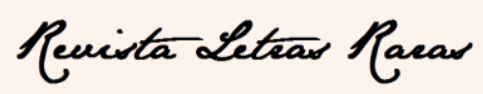

ISSN: $2317-2347$ - v. 8, n. 3 (2019)

determinam as modalidades e os objetivos de programas institucionais viabilizados para aprendizes de segundas línguas (KUMARAVADIVELU, 2012, p. 26) ${ }^{13}$.

Além disso, no módulo Analyzing, o autor pondera que

para desempenhar seus deveres de modo responsável e com sucesso, professores de segunda língua precisam desenvolver o saber e a habilidade necessária para analisar e compreender as necessidades, a motivação e a autonomia dos aprendizes. O que torna essa análise e compreensão tão complicada e desafiadora é o fato de que as necessidades dos alunos, sua motivação e autonomia são determinadas por uma combinação de demandas individuais, institucionais, governamentais e sociais. Essas demandas às vezes competem entre si, mudando de acordo com o contexto e a época (KUMARAVADIVELU, 2012, p. 37) ${ }^{14}$.

A examinar os diferentes referenciais de competências/saberes do professor de línguas tratados até agora (ALMEIDA FILHO, 2005; NEWBY et al., 2007; SCHART e LEGUTKE, 2012; ENDE et al., 2013; e KUMARAVADIVELU, 2012), percebe-se que há relativamente poucas menções explícitas a aspectos da política linguística. Não obstante, o espaço dado ao tema parece aumentar ao longo do tempo. Nos excertos analisados, o foco recai, principalmente, sobre o reconhecimento em si da dimensão política do ensino de línguas, materializada em documentos oficiais e diretrizes curriculares que vêm de instâncias superiores e precisam ser respeitadas (cf. ENDE et al., 2013). Para além disso, Newby et al. (2007) se preocupam também em formular descritores para aferir a competência do professor em operacionalizar essas diretivas na sala de aula, ao lado do respeito a outros fatores como necessidades cognitivas e emocionais dos aprendizes, assim como expectativas de terceiros (pais, empregador, por exemplo) (ibid., p. 16). No entanto, Kumaravadivelu (2012) é o único dos autores consultados que chama a atenção explicitamente para a concorrência e os possíveis conflitos que possam surgir entre essas demandas variadas, reivindicando do professor uma posição crítica com relação a essa condição do ensino de línguas.

\footnotetext{
${ }^{13}$ No original: "[There are] educational factors such as language policies and language planning put in place by governmental or educational agencies. These factors determine the types and goals of instructional programs made available to L2 learners."

${ }^{14}$ No original: "[...] in order to carry out their duties responsibly and successfully, L2 teachers must develop the knowledge and skill necessary to analyze and understand learner needs, learner motivation, and learner autonomy. What makes such analysis and understanding so complicated and challenging is that learner needs, motivation, and autonomy are determined by a combination of individual, institutional, governamental, and societal demands. These demands, sometimes competing with each other, change from context to context and from time to time."
} 


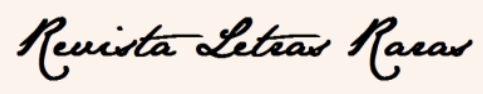

ISSN: 2317-2347 - v. 8, n. 3 (2019)

Na próxima seção, iremos discutir como os interesses divergentes identificados por Kumaravadivelu se manifestam atualmente no ensino de alemão nas escolas brasileiras.

\section{Política linguística na era da globalização: o exemplo do ensino de alemão no Brasil}

Conforme já mencionado na introdução, o renomado especialista alemão de didática de línguas Herbert Christ (1992, p. 60) considera a política linguística "uma disciplina basilar da teoria do ensino-aprendizagem de línguas estrangeiras"15, de importância comparável às ciências de aporte da área como a linguística e a pedagogia. De acordo com o autor, as condições institucionais do ensino de línguas são reflexo direto da política linguística e precisam ser levantadas empiricamente e reconhecidas pelos profissionais que nelas atuam.

No caso da língua alemã, há muito tempo o fomento ao ensino do idioma no exterior é visto pelo governo alemão como um importante recurso para estreitar os laços culturais e econômicos com outros países. Um exemplo patente dessa política consiste na ampla rede dos atualmente 159 Institutos Goethe espalhados em 98 países ao redor do mundo. ${ }^{16}$ Como explica Augspurger (1993), palestrante do Instituto Goethe por ocasião do $2^{\circ}$ Congresso Brasileiro de Professores de Alemão, em 1991:

Nós não fazemos propaganda no sentido político, não queremos missionar e não pretendemos mostrar arrogância nacional; nenhuma língua é "melhor" que a outra; mas, enquanto professores de alemão, representamos a Alemanha e a língua alemã, assim como a rica cultura alemã e sua história e civilização, principalmente da Alemanha contemporânea (AUGSPURGER, 1993, p. 137, grifo e aspas no original $)^{17}$.

Como ponderei em outro artigo (UPHOFF, 2015, p. 282), ressoa, nessas palavras, a preocupação de que o engajamento para com o ensino de alemão no exterior pudesse ser mal interpretado, como uma atitude pouco ética e até prepotente. Ora, é interessante observar que em uma publicação do ministério alemão das relações

\footnotetext{
15 No original: "[Sprachenpolitik ist] eine der Grundlagendisziplinen der Theorie des Lehrens und Lernens fremder Sprachen [...]."

${ }^{16}$ Dados do sítio eletrônico [https://www.goethe.de/de/wwt.html] (Acesso em: 20/06/2019).

17 No original: "Wir machen keine Propaganda im politischen Sinne, wollen nicht missionieren und zeigen dabei keine nationale Überheblichkeit; keine Sprache ist „,besser" als die andere, aber wir vertreten als Deutschlehrer Deutschland und die deutsche Sprache und werben und unterrichten mit der deutschen Sprache und auch für die reiche deutsche Kultur und Geschichte und Landeskunde, insbesondere des Deutschland von heute. "
} 


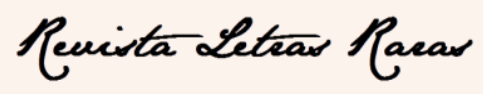

ISSN: $2317-2347$ - v. 8, n. 3 (2019)

exteriores (Auswärtiges Amt) de 2015, ou seja, duas décadas depois da palestra de Augspurger (1993), essa política é pronunciada com muito mais objetividade e autoconfiança:

O fomento da língua é um instrumento particularmente sustentável da política externa. Ele promove o diálogo, o intercâmbio e a colaboração entre pessoas e culturas, transmite uma imagem positiva da Alemanha no exterior e traz pessoas para a Alemanha. Com os jovens aprendizes de alemão de hoje, ganhamos parceiros importantes para a política, economia, cultura, ciência e pesquisa de amanhã (AUSWÄRTIGES AMT, 2015, p. 3$)^{18}$.

A citação foi retirada de um relatório do governo alemão que, desde 1985, levanta periodicamente o número dos aprendizes de ALE no mundo inteiro. Como se observa na edição de 2015 do documento:

Em muitos lugares do mundo, a língua alemã goza de uma procura crescente. Isso é também uma consequência da globalização. Países geograficamente distantes estão se tornando mais próximos para muitos jovens na China e no Brasil. A Alemanha consegue competir de forma excelente nessa concorrência internacional pelas melhores cabeças - considerando que, nos últimos anos, o nosso país se tornou mais atrativo enquanto local internacionalmente reconhecido de economia, ciências e pesquisa para pessoas do mundo inteiro (AUSWÄRTIGES AMT, ibid.) $)^{19}$.

A globalização, com seu "fluxo de capital, mercadorias, pessoas, imagens e discursos que corre pelo mundo"20 (THÜRMANN, 2016, p. 51), é vista, portanto, como um fenômeno que facilita o contato com outras línguas e culturas, mas, ao mesmo tempo, acirra a concorrência global "pelas melhores cabeças".

É nesse contexto que precisa ser considerada também a iniciativa PASCH (abreviação de Schulen - Partner der Zukunft, "Escolas - parceiras do futuro"), um programa do governo alemão inaugurado em 2008 que visa montar uma rede global de escolas de excelência de ensino fundamental e médio que promovem o ensino de ALE.

\footnotetext{
${ }^{18}$ No original: "Sprachförderung ist ein besonders nachhaltiges außenpolitisches Instrument. Sie fördert Dialog, Austausch und Zusammenarbeit zwischen Menschen und Kulturen, vermittelt ein positives Deutschlandbild im Ausland und bringt Menschen nach Deutschland. Mit den jungen Deutschlernenden von heute gewinnen wir wichtige Partner in Politik, Wirtschaft, Kultur, Wissenschaft und Forschung für morgen."“

${ }^{19}$ No original: "Die deutsche Sprache erfreut sich in vielen Teilen der Welt einer wachsenden Nachfrage. Dies ist nicht zuletzt eine Folge der Globalisierung. Geografisch weit entfernte Länder rücken für viele junge Menschen in China oder Brasilien in erreichbare Nähe. Deutschland kann sich in diesem internationalen Wettbewerb um die besten Köpfe hervorragend behaupten - hat unser Land doch in den vergangenen Jahren an Attraktivität als international anerkannter Wirtschafts- und ebenso auch Wissenschafts- und Forschungsstandort für Menschen aus aller Welt hinzugewonnen."

${ }^{20}$ No original: "Strom von Kapital, Waren, Menschen, Bildern und Diskursen [...], der [...] um die Welt fließt $[\ldots]$ ".
} 


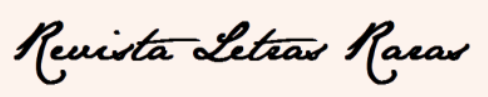

ISSN: 2317-2347 - v. 8, n. 3 (2019)

Inicialmente projetado para integrar mil escolas ao redor do mundo, a iniciativa já superou essa meta abarcando atualmente cerca de 1.800 instituições. ${ }^{21}$ Como frisa o relatório citado do governo alemão (AUSWÄRTIGES AMT, 2015, p. 27), o programa PASCH exerce uma função destacada (Leuchtturmfunktion, literalmente "função de farol") na empreitada de aumentar os números dos aprendizes de ALE no Brasil, no âmbito escolar. Com atualmente 43 escolas conveniadas ${ }^{22}$, o país apresenta a maior infraestrutura do programa no mundo ibero-americano, à frente também de países como Espanha, Portugal, Argentina e México. ${ }^{23}$

O apoio dado a essas escolas compreende doação de materiais didáticos e medidas de formação continuada para os professores, mas, dependendo do caso, também recursos técnicos como data-show e lousa digital, além de bolsas de viagem para a Alemanha para professores e alunos. Ademais, através do sítio eletrônico do programa, é possível encontrar escolas parceiras de outros países e continentes para desenvolver atividades didáticas conjuntas em língua alemã. Em todas as escolas conveniadas os alunos são preparados para obter certificados oficiais de proficiência em língua alemã. Nas instituições que disponibilizam uma carga horária maior ao ensino do idioma (por volta de seis horas/aula semanais), viabilizando, assim, a construção de uma proficiência linguística mais avançada, em nível B2/C1 de acordo com o Quadro, existe a possibilidade de prestar o Deutsches Sprachdiplom (DSD II), que isenta o aluno interessado em fazer um curso universitário na Alemanha da prova de conhecimentos linguísticos, obrigatória para entrar em uma faculdade alemã para falantes não-nativos.

Para ser conveniado como “escola DSD” (o termo oficial em língua alemã é DSD-Schulen), o colégio precisa seguir as diretrizes do Rahmenplan (ZfA, 2009), currículo para o ensino de ALE estabelecido pela Zentralstelle für das Auslandsschulwesen, órgão público da Alemanha que supervisiona as escolas alemãs no exterior.

\footnotetext{
${ }^{21}$ Cf. dados no sítio eletrônico do programa em [https://www.pasch-net.de/de/par.html] (Acesso em: 21/06/2019).

${ }^{22}$ Cf. dados em [http://weltkarte.pasch-net.de/] (Acesso em: 21/06/2019).

${ }^{23}$ Cf. números do mapa-mundi disponibilizado pelo programa PASCH em [http://weltkarte.paschnet.de/2015/map/files/print/PASCH-Weltkarte-Partnerschulen-201903.pdf] (Acesso em: 21/06/2019).
} 


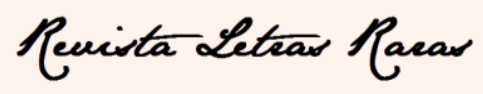

ISSN: $2317-2347$ - v. 8, n. 3 (2019)

A grande maioria das escolas que integram a iniciativa PASCH no Brasil é particular, mas há também escolas públicas, como as Escolas Estaduais de Ensino Profissionalizante Juarez Távoa e Paulo VI ${ }^{24}$, na cidade de Fortaleza, Ceará.

A estrutura do PASCH, criada em pouco mais de dez anos pelo governo alemão, impressiona, contrastando de maneira acentuada com o fomento ao ensino escolar de LE fornecido pela legislação brasileira. Salvo louváveis exceções, como os Centros de Estudo de Línguas (CELs) do estado de São Paulo, há pouco incentivo para a aprendizagem de uma segunda ou terceira língua estrangeira na educação básica, também no ensino médio, que teve a oferta obrigatória do espanhol minada pela lei $\mathrm{n}^{\mathrm{o}}$ 13.415, de 16 de fevereiro de 2017. É possível concluir que não há apoio institucional, pelo menos em nível nacional, ao ensino de alemão na escola brasileira. Essa ausência abre espaço para a iniciativa $\mathrm{PASCH}$ do governo alemão, especialmente na rede particular de ensino, onde se costuma valorizar mais a construção de uma proficiência plurilíngue como meio de uma educação ampla, capaz de levar a uma vida profissional bem-sucedida.

Já em 1992, Christ questionava: "Se não houvesse o ensino institucionalizado de línguas estrangeiras, o ensino-aprendizagem dessas línguas certamente seria possível também - mas em que extensão, com que meios, em que lugar?"25 (CHRIST, 1992, p. 60). Olhando para as condições políticas do ensino de alemão na escola brasileira, é fácil perceber que o espaço desse idioma existe, nas proporções atuais, principalmente por causa da política alemã - e não da brasileira - de fomento à língua. Essa política abre oportunidades muito interessantes para os alunos brasileiros, mas vem também acompanhada por certas exigências metodológicas e curriculares, em função dos materiais disponibilizados (via de regra livros didáticos internacionais, produzidos na Alemanha) e também do Rahmenplan, que precisam ser refletidas pelos professores. Nesse cenário, julgamos importante indagar como essas condições políticas do ofício do professor de alemão devem ser endereçadas no âmbito da licenciatura em Letras. Na

\footnotetext{
${ }^{24}$ Essas duas escolas fazem parte da categoria Fit-Schulen, que (ainda) não oferecem uma carga horária de língua alemã tão elevada quanto as DSD-Schulen, cf. [http://weltkarte.pasch-net.de/] (Acesso em: 21/06/2019). Há no Brasil, atualmente, 20 escolas conveniadas na categoria Fit-Schulen e 19 na categoria DSD-Schulen, além de quatro colégios na categoria Deutsche Auslandsschulen que oferecem também o diploma alemão de conclusão do ensino médio, o Abitur.

${ }^{25}$ No original: "Wenn es Fremdsprachenunterricht als Institution nicht gäbe, dann wäre zwar auch Lehren und Lernen fremder Sprachen möglich - aber in welchem Umfang, mit welchen Mitteln, an welchem Ort?"
} 


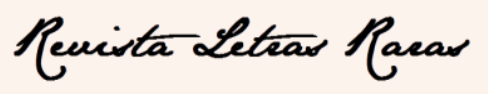

ISSN: 2317-2347 - v. 8, n. 3 (2019)

próxima seção, com base em Kumaravadivelu (2012), teceremos algumas reflexões iniciais a respeito, que poderão servir de ponto de partida para uma discussão mais ampla.

\section{A importância da dimensão política na formação inicial de professores de alemão}

Ao longo deste artigo, procuramos investigar o lugar da política linguística na formação inicial de professores de ALE no Brasil. Discutimos diversos modelos de competências consideradas necessárias ao ofício do professor de LE e examinamos também diferentes aspectos ligados ao conceito de competência, bem como sua relação com o termo "saber". Argumentamos, com base em Christ (1992), que a política linguística apresenta uma importância basilar para o ensino de línguas, uma vez que ela define as condições institucionais em que o ensino - principalmente na educação básica - pode ocorrer. O exemplo da iniciativa PASCH do governo alemão mostrou que, além da política nacional do país em que se estuda determinado idioma, também outras nações estão interessadas em fomentar a oferta de sua língua oficial no exterior, no intuito de aumentar o seu raio de difusão e, com isso, obter vantagens políticas, econômicas e científicas no atual mundo globalizado. Ora, quais são as consequências dessa competição das línguas no mundo globalizado para o curso de licenciatura? Como a dimensão política do ensino de línguas deve ser tratada na graduação e que tipo de saber ou competência do professor em formação deve-se almejar nesse âmbito?

Para responder a essa pergunta, vale lembrar as palavras de Perrenoud (2000, p. 172), citadas na seção 2 , de que as competências do professor não podem ser formuladas de forma objetiva, uma vez que são construídas a partir de certas noções teóricas e ideológicas. Dessa forma, gostaríamos de embasar nossas reflexões finais nos três parâmetros propostos por Kumaravadivelu (2003, 2006) - particularidade, praticabilidade e possibilidade -, os quais, segundo o autor, "também podem funcionar como princípios operantes para a formação de professores de línguas"26 (KUMARAVADIVELU, 2012, p. 12).

\footnotetext{
${ }^{26}$ No original: "[As part of postmethod pedagogy, I have proposed three parameters,] which can funcion as operating principles for language teacher education as well."
} 


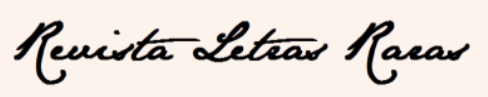

ISSN: 2317-2347 - v. 8, n. 3 (2019)

Assim, de acordo com o princípio da particularidade, a formação docente deverá levar em consideração também as condições locais do ensino, incluindo o reconhecimento das leis e diretrizes que definem e estruturam a oferta institucional de determinado idioma nas escolas. Para garantir o saber coletivo $e$ explícito desses condicionantes (cf. o exposto acerca dos binômios coletivo/individual e explícito/implícito na seção 2), é fundamental que esses tópicos sejam tratados já no curso de licenciatura em Letras.

O princípio da praticabilidade, por sua vez, visa superar a dicotomia entre teoria e prática e dar também ao professor a oportunidade de teorizar sobre a sua prática de ensino. Kumaravadivelu (2012, p. 14) explica que, para viabilizar esse objetivo, o professor em formação precisa ser munido com ferramentas de observação e pesquisa para investigar, de forma sistemática, os acontecimentos da sala de aula. Acreditamos que, nesse âmbito, há um potencial menor para refletir sobre a dimensão política do ensino de línguas durante a graduação, uma vez que é preciso tempo e experiência em sala de aula para sentir as tensões entre a teoria e a prática e estimular o processo de teorização do professor em formação. Contudo, dependendo da localização, é possível organizar, já durante o curso de licenciatura, visitas a escolas de perfil variado para proporcionar uma vivência das diferentes condições institucionais em que o ensino de alemão ocorre. Na cidade de São Paulo, temos o privilégio de dispor de todas as categorias de escolas conveniadas ao programa PASCH (Fit-Schulen, DSD-Schulen e deutsche Auslandsschulen), além de Centros de Estudos de Línguas (CELs), que atendem os alunos da rede pública de ensino. As visitas a essas instituições proporcionam uma visão diferenciada acerca do futuro mercado de trabalho, aguçando a percepção dos licenciandos referente ao valor de uma política educacional em prol do plurilinguismo.

Finalmente, o princípio da possibilidade defende a construção de uma consciência crítica por parte do professor em formação, no que diz respeito às expectativas e demandas relacionadas a sua profissão em um mundo globalizado (cf. KUMRAVADIVELU, 2012, p. 15). Nesse contexto, vale mencionar, por exemplo, as tensões entre metodologias locais e globais que podem aflorar quando se trabalha com livros didáticos internacionais ou com um programa de ensino elaborado por uma instância estrangeira - um cenário bastante provável nas escolas conveniadas ao 


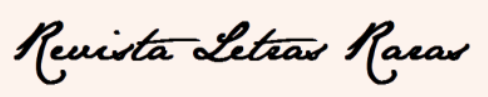

ISSN: 2317-2347 - v. 8, n. 3 (2019)

programa PASCH, considerando o conjunto de orientações didáticas e curriculares que recebem da ZfA. Como formula Kramsch (2014, p. 299), "a competição entre estilos de ensino é também uma competição entre o valor simbólico de diferentes línguas no mercado global" 27 .

Como a praticabilidade, também o princípio da possibilidade necessita de tempo e precisa ser alimentado aos poucos, perpassando todos os ciclos da formação continuada. No entanto, assim como no caso do princípio da praticabilidade, também aqui nos parece importante criar as bases já na formação inicial do professor de ALE, através da conscientização sobre essa configuração peculiar do ensino de alemão, de haver pouco interesse político, em nível nacional, de reservar espaço para a língua alemã na rede pública de ensino, mas, em contraposição, muito interesse por parte da Alemanha em fomentar o ensino de seu idioma, principalmente nas escolas particulares onde as condições para implantar uma segunda ou terceiro língua na grade curricular são mais favoráveis.

Concluindo, defendemos a importância de abordar a dimensão política do ensino de ALE já na formação inicial do professor, iniciando com a construção de um corpo de conhecimentos explícitos acerca das leis e diretrizes curriculares oriundas de todas as instâncias envolvidas que moldam as condições institucionais em que o ensino pode ser realizado. Certamente, esse "saber profissional", na terminologia de Kumaravadivelu (2012), representa apenas um dos ingredientes que compõem as competências do professor, mas trata-se, a nosso ver, de um conhecimento necessário para o desenvolvimento das outras habilidades, bem como da consciência crítica, que são construídas progressivamente ao longo da vida profissional.

\section{REFERÊNCIAS}

ALMEIDA FILHO, J. C. P. O ensino de línguas no Brasil desde 1978: e agora? In: ALMEIDA FILHO, J. C. P. Linguística aplicada, ensino de línguas \& comunicação. Campinas: Pontes, 2005, p. 89-101.

AUGSPURGER, H. J. Möglichkeiten der Werbung für DaF-Unterricht. In: CONGRESSO BRASILEIRO DE PROFESSORES DE ALEMÃO, 2. 19-23/07/1991, São Leopoldo. Anais... São Leopoldo: Unisinos, 1993, p. 136-137.

\footnotetext{
${ }^{27}$ No original: "The competition between teaching styles is also a competition between the symbolic value of different languages on the global market [...]".
} 


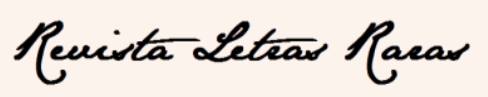

ISSN: 2317-2347 - v. 8, n. 3 (2019)

AUSWÄRTIGES AMT. Deutsch als Fremdsprache weltweit. Datenerhebung 2015. Berlin: Bonifatius, 2015. Disponível em: [https://www.goethe.de/resources/files/pdf37/Bro_ Deutschlernerhebung_final2. pdf]. Acesso em: 19/04/2019.

BRASIL. Lei $n^{o} 13.415$ de 16 de fevereiro de 2017. Disponível em: [http://www.planalto.gov.br/ccivil_03/_Ato2015-2018/2017/Lei/L13415.htm]. Acesso em: $15 / 06 / 2019$.

CHRIST, H. Sprachenpolitik als Bedingung der Möglichkeit des Fremdsprachenunterrichts. In: BAUSCH, H. R.; CHRIST, H.; KRUMM, H. J. (Org.). Fremdsprachenunterricht und Sprachenpolitik als Gegenstand der Forschung. Bochum: Brockmeyer, 1992, p. 55-61.

CONSELHO DA EUROPA. Quadro europeu comum de referência para línguas: aprendizagem, ensino, avaliação. Porto: Edições ASA, 2001.

CONSOLO, D. A.; PORTO, C. F. C. Competências do professor no processo de ensinoaprendizagem de língua estrangeira. Horizontes de Linguística Aplicada, Brasília, v. 10, n. 2, p. 65-86, 2011.

ENDE, K.; MOHR, I. (Org.). Glossar: Fachbegriffe für DaF-Lehrkräfte. München: Klett-Langenscheidt, 2015.

ENDE, K.; GROTJAHN, R.; KLEPPIN, K.; MOHR, I. (Org.). Curriculare Vorgaben und Unterrichtsplanung. München: Klett-Langenscheidt, 2013.

KRAMSCH, C. Teaching foreign languages in an era of globalization: introduction. The Modern Language Journal, v. 98, n. 1, p. 296-311, 2014.

KRUMM, H. J. Sprachenpolitische, bildungspolitische und gesellschaftliche Rahmenbedingungen. In: BURWITZ-MELZER, E.; MEHLHORN, G.; RIEMER, C.; BAUSCH, K. R.; KRUMM, H. J. (Org.). Handbuch Fremdsprachenunterricht. 6., völlig überarbeitete und erweiterte Auflage. Tübingen: Francke, 2016, p. 45-51.

KRUMM, H. J.; RIEMER, C. Ausbildung von Lehrkräften für Deutsch als Fremdsprache und Deutsch als Zweitsprache. In: KRUMM, H. J.; FANDRYCH, C.; HUFEISEN, B.; RIEMER, C. (Org.). Deutsch als Fremd- und Zweitsprache. Ein internationales Handbuch, v. 2. Berlin/New York: de Gruyter, 2010, p. 1340-1351.

KUMARAVADIVELU, B. Language teacher education for a global society: a modular model for knowing, analyzing, recognizing, doing, and seeing. New York: Routledge, 2012.

KUMARAVADIVELU, B. Understanding language teaching: from method to postmethod. New York: Routledge, 2006.

KUMARAVADIVELU, B. Beyond methods: macrostrategies for language teaching. New Have: Yale University Press, 2003.

NEWBY, D.; ALLAN, R.; FENNER, A. B.; JONES, B.; KOMOROWSKA, H.; SOGHIKYAN, K. EPOSA - Europäisches Portfolio für Sprachlehrende in Ausbildung: ein Instrument zur Reflexion, 2007. Disponível em: [https://archive.ecml.at/mtp2/publications/C3_Epostl_D_internet.pdf]. Acesso em: $15 / 06 / 2019$. 


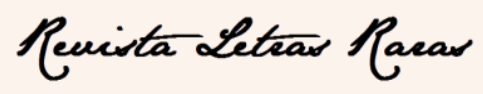

ISSN: 2317-2347 - v. 8, n. 3 (2019)

PERRENOUD, P. Dez novas competências para ensinar. Porto Alegre: Artes Médicas Sul, 2000.

PRABHU, N. S. There is no best method - why? TESOL Quarterly, v. 24, n. 2, p. 161176, 1990.

RAJAGOPALAN, K. Política linguística: do que é que se trata, afinal? In: NICOLAIDES, C.; SILVA, K. A.; TILIO, R.; ROCHA, C. H. (Org.). Política e políticas linguísticas. Campinas: Pontes, 2013, p. 19-42.

SCHART, M.; LEGUTKE, M. Lehrkompetenz und Unterrichtsgestaltung. München: Klett-Langenscheidt, 2012.

THÜRMANN, Eike. Globalisierung und Standardisierung in ihrer Auswirkung auf das Lernen und Lehren von Sprachen. In: BURWITZ-MELZER, E.; MEHLHORN, G.; RIEMER, C.; BAUSCH, K. R.; KRUMM, H. J. (Org.). Handbuch Fremdsprachenunterricht. 6., völlig überarbeitete und erweiterte Auflage. Tübingen: Francke, 2016, p. 51-55.

UPHOFF, D. O lugar da criticidade na formação inicial de professores de alemão. In: FERRAZ, D. M.; KAWACHI-FURLAN, C. L. (Org.). Educação linguística em línguas estrangeiras. Campinas: Pontes, 2018, p. 231-247.

UPHOFF, D. A política linguística nos Congressos Brasileiros de Professores de Alemão (1989-2015). In: UPHOFF, D.; FISCHER, E.; AZENHA, J.; PEREZ. J. P. (Org.). 75 anos de alemão na USP: reflexões sobre uma germanística brasileira. São Paulo: Humanitas, 2015, p. 275-295.

ZENTRALSTELLE FÜR DAS AUSLANDSSCHULWESEN [ZfA]. Rahmenplan Deutsch als Fremdsprache für das Auslandsschulwesen. Köln: Bundesverwaltungsamt, 2009. 